\section{A case of episodic and refractory arthritis due to a novel variant of NLRP12}

It was with great interest that I read the paper by Gupta et al describing novel NLRP12 variant is linked to familial cold autoimmunity syndrome phenotype. ${ }^{1}$ Here, we reported a patient present with phenotypes of episodic and refractory arthritis due to another novel variant in NLRP12.

A 28-year-old man presented at the age of 20 years with episodic pain, swelling and erythematous skin rash in his wrists, metacarpophalangeal, interphalangeal, knee and ankle joints. His symptoms typically occur once per 1-2 months and sometimes with the increased frequency of episodes to three to four times in 1 week. No identifiable factors were found to trigger the onset. Symptoms lasted from several hours to 3-5 days and subsided spontaneously. His erythrocyte sedimentation rate and C-reactive protein level were elevated during periods of symptoms with normalisation during remission. He was negative for rheumatoid factor, antinuclear antibody and anticitrullinated peptide antibody. No synovitis was detected by ultrasound or MRI in the affected joints. Numerous empirical treatments including nonsteroidal antiinflammatory drugs, colchicine, glucocorticoid (prednisone $10 \mathrm{mg} /$ day), methotrexate and hydroxychloroquine failed to reduce recurrent episodes or relief symptoms. Then, after a sudden onset, only a wait to see strategy can be used for him to wait for the spontaneous remission.

Whole exome sequencing revealed a novel heterozygous mutation in the exon 3 of the NLRP12 gene (c.1771C>A: p.L591M) on chromosome 19. By using Sanger Sequencing, we did not find this mutation in his parents, indicating that it might be a de novo mutation. This missense variant is extremely rare and absent in $>200000$ individuals who have been well-sequenced with high depth at the NLRP12 region in gnomAD and TOPMed. It is predicted to be deleterious and probably damaging the protein function by different in silico computational tools including PANTHER, polyphen2 and SIFT. NLRP12 is a novel member of the inflammasome complex and acts as a negative regulator of inflammation. ${ }^{2}{ }^{3}$ We found peripheral mononuclear cells (PBMC) from this patient showed markedly increased NF- $\mathrm{KB}$ activity and IL-1 $\beta$ production after tumour necrosis factor alpha (TNF $\alpha)$ stimulation, as compared with arthritis patients noncarrying this variant and healthy controls, supporting the functional significance of this heterozygous mutation in NLRP12.

Compared with the patient under discussion in this journal present with familial cold autoimmunity syndrome phenotype,${ }^{14}$ the distinct clinical manifestations in our case are recurrent transient episodes of arthritis and erythematous skin rash. This patient has ever been diagnosed as palindromic rheumatism and undifferentiated arthritis. A diagnosis of NLRP12 associated systemic autoinflammatory disorder was therefore made. Due to non-availability of interleukin- 1 inhibitor in China, the patient was treated with tofacitinib and had a modest benefit from it. Our case highlights the importance of screening autoinflammatory disorder and NLRP12 in patients with unexplained episodic and refractory arthritis.

Jiajia Wang, Qian Zhang, Lingxiao Xu, Chengyin Lv, Rui Liu, Miaojia Zhang, Wenfeng Tan $\odot$

Department of Rheumatology, The First Affiliated Hospital of Nanjing Medical University, China, Nanjing, Jiangsu, China

Correspondence to Dr Wenfeng Tan, Department of Rheumatology, The First Affiliated Hospital of Nanjing Medical University, Nanjing 210029, China; tw2006@njmu.edu.cn

Contributors The conception and design of the correspondence, acquisition of data, and analysis and interpretation of data: WT, MZ and JW; Involved in care of the patient: JW and WT; Drafting the article: JW, LX and WT; Revising it critically for important intellectual content: JW, QZ, LX, RL and CL; Final approval of the version to be submitted: all authors; Agreement to be accountable for all aspects of the work in ensuring that questions related to the accuracy or integrity of any part of the work are appropriately investigated and resolved: all authors.

Funding This work was supported from the National Natural Science Foundation of China (NSFC): 81971532 (WT).

Competing interests None declared.

Patient consent for publication Not required.

Provenance and peer review Not commissioned; internally peer reviewed.

(c) Author(s) (or their employer(s)) 2020. No commercial re-use. See rights and permissions. Published by BMJ.

JW and QZ contributed equally.

JW and QZ are joint first authors.

$\mathrm{LX}, \mathrm{CL}, \mathrm{RL}$ and $\mathrm{MZ}$ are joint senior authors.

\section{Check for updates}

To cite Wang J, Zhang Q, Xu L, et al. Ann Rheum Dis Epub ahead of print: [please include Day Month Year]. doi:10.1136/annrheumdis-2020-217023

Received 20 January 2020

Accepted 24 January 2020

Ann Rheum Dis 2020;0:1. doi:10.1136/annrheumdis-2020-217023

ORCID iD

Wenfeng Tan http://orcid.org/0000-0002-5160-2023

\section{REFERENCES}

1 Gupta L, Ahmed S, Singh B, et al. Novel NLRP12 variant presenting with familial cold autoimmunity syndrome phenotype. Ann Rheum Dis 2019:annrheumdis-2019-216158 (Epub ahead of print: 24 Aug 2019).

2 Coulon P-G, Dhanushkodi N, Prakash S, et al. NIrp3, NLRP12, and IFI16 inflammasomes induction and caspase-1 activation triggered by virulent HSV-1 strains are associated with severe corneal inflammatory herpetic disease. Front Immunol 2019;10:1631.

3 Zaki MH, Vogel P, Malireddi RKS, et al. The NOD-like receptor NLRP12 attenuates colon inflammation and tumorigenesis. Cancer Cell 2011;20:649-60.

4 Ghosh K. NLRP12 gene mutation in India: case finding and diagnosis made easy in the days of whole exome sequencing. Ann Rheum Dis 2019:annrheumdis-2019-216270 (Epub ahead of print: 20 Sep 2019). 